\title{
Descrição de um novo gênero amazônico de Neocoelidiinae (Hemiptera, Auchenorrhyncha, Cicadellidae) ${ }^{1}$
}

\author{
Ana Paula Marques-Costa ${ }^{2} \&$ Rodney R. Cavichioli ${ }^{2}$
}

\begin{abstract}
1 Contribuição número 1668 do Departamento de Zoologia, Universidade Federal do Paraná.
2 Programa de Pós-graduação em Entomologia, Departamento de Zoologia, Universidade Federal do Paraná. Caixa Postal 19020, 81531-980 Curitiba, Paraná, Brasil.E-mail: apcm@ufpr.br; cavich@ufpr.br
\end{abstract}

\begin{abstract}
Description of a new Amazonian genus of Neocoelidiinae (Hemiptera, Auchenorrhyncha, Cicadellidae). A new genus of Neocoelidiinae, Scopocoelidia gen. nov., and its type-species, Scopocoelidia volsellata sp. nov., are described from the Amazonian Region. This new genus has external morphology very similar to that of Coelidiana Oman, 1936, but it can be easily distinguished from this and the other Neocoelidiinae genera by the features of the male genitalia, being the only genus in which the anal tube has brushes of bristles ventrally. The females of this genus are unknown. Illustrations and the geographical distribution of the studied species are given. KEY WORDS. Geographical distribution; morphology; Scopocoelidia; Scopocoelidia volsellata; taxonomy.
\end{abstract}

RESUMO. Um gênero novo de Neocoelidiinae, Scopocoelidia gen. nov., e sua espécie-tipo, Scopocoelidia volsellata sp. nov., são descritos da Região Amazônica. Este novo gênero possui morfologia externa muito semelhante à de Coelidiana Oman, 1936, mas pode ser facilmente separado deste e dos demais gêneros de Neocoelidiinae pelas características da genitália masculina, sendo o único gênero que possui tubo anal com tufos de cerdas ventralmente. As fêmeas deste gênero não são conhecidas. São fornecidas ilustrações e a distribuição geográfica da espécie estudada.

PALAVRAS-CHAVE. Distribuição geográfica; morfologia; Scopocoelidia; Scopocoelidia volsellata; taxonomia.

Neocoelidiinae compreende uma única tribo, Neocoelidiini, atualmente com 160 espécies em 26 gêneros. No Brasil, foram registradas 54 espécies em 15 gêneros. A subfamília é principalmente neotropical, havendo apenas quatro gêneros com registro para a Região Neártica: Coelella DeLong, 1953, Neocoelidia Gillette \& Baker, 1895, Cocoelidia DeLong, 1953 e Neocoelidiana DeLong, 1953 (Nielson \& KNight 2000).

A subfamília inclui cigarrinhas de tamanho pequeno a médio (5,0-12,0 mm), de coloração geral normalmente em tons pálidos, que podem ser identificadas pelo seguinte conjunto de características: cabeça projetada anteriormente, freqüentemente com carena marginal; coroa elevada e achatada entre os olhos; ocelos na margem anterior da cabeça ou próximos a esta; suturas frontogenais estendendo-se ou não até os ocelos; antenas extremamente longas, com escapo e pedicelo bem desenvolvidos; clípeo com ou sem intumescimento mediano ou tubérculo; mesotórax freqüentemente bem desenvolvido, a pleura estendendo-se até a região do esterno, dando aos neocelidiíneos um aspecto intumescido ventralmente; venação da asa anterior geralmente indistinta, exceto apicalmente; $R_{4+5}$ e $\mathrm{M}_{1+2}$ da asa posterior geralmente confluentes pré-apicalmente.

Dietrich (2003) redescreveu a subfamília, redefinindo-a para englobar três gêneros antes pertencentes à Nirvaninae -
Krocodona Kramer, 1964 (com nova sinonímia, Krocobella Kramer, 1964), Krocozzota Kramer, 1964, e Krocarites Dietrich \& Vega, 1995 - e mais dois gêneros novos - Retrolidia e Krocolidia. Afirmou que apesar destes gêneros possuírem cabeça fortemente projetada anteriormente e lobos supra-antenais reduzidos, diferindo do conceito de Neocoelidiinae sensu KrAmer (1964), foram incluídos em Neocoelidiinae por exibirem algumas características comuns aos neocelidiíneos, prováveis sinapomorfias para a subfamília, tais como: valva subgenital (esternito VIII) do macho fusionado às placas subgenitais, mas articulada ao pigóforo; pigóforo com dente ou espinho posteroventral e asa posterior com as veias $R_{4+5}$ e $M_{1+2}$ confluentes.

Entretanto, não há estudos específicos sobre as relações filogenéticas entre os gêneros e espécies de Neocoelidiinae. Vários caracteres citados por DieTrich (2004) são muito variáveis entre os gêneros da subfamília, e provavelmente não constituem sinapomorfias para o grupo. Faz-se necessário um estudo mais aprofundado, para uma melhor caracterização dos gêneros e para testar a monofilia da subfamília.

Este trabalho inclui a descrição de um gênero novo de Neocoelidiinae, Scopocoelidia gen. nov., e de uma espécie nova, S. volsellata sp. nov. São fornecidas ilustrações e a distribuição geográfica da espécie estudada. 


\section{MATERIAL E MÉTODOS}

As abreviaturas citadas no texto correspondem às seguintes instituições, responsáveis pelo empréstimo do material: Coleção de Invertebrados do Instituto Nacional de Pesquisas da Amazônia (INPA), Manaus, Amazonas, Brasil; Coleção de Entomologia Pe. Jesus Santiago Moure do Departamento de Zoologia da Universidade Federal do Paraná (DZUP), Curitiba, Paraná, Brasil e Muséum National d'Histoire Naturelle (MNHN), Paris, França. As medidas são fornecidas em milímetros.

Para a análise das estruturas da genitália, seguiu-se a mesma metodologia adotada por MARQues-Costa \& CAVICHIOLI (2006). O holótipo foi fotografado utilizando-se câmera fotográfica digital Sony modelo Cyber-Shot DSC-S75 diretamente acoplada em microscópio estereoscópico Zeiss Stemi 2000-C pertencente ao Laboratório de Sistemática e Bioecologia de Coleoptera da Universidade Federal do Paraná.

A terminologia adotada segue principalmente os trabalhos de Kramer (1964) e Young $(1968,1977,1986)$, exceto para as estruturas da cabeça, cuja terminologia segue o trabalho de Hamilton (1981), conforme sugerido por Mejdalani (1998); a venação das asas segue CoMstock \& NeEDHAM (1898, 1899), como sugerido por TRIPLEHORN \& JoHNSON (2005) e OMAN (1949), e a posição das cerdas da tíbia posterior segue Rakitov (1998).

\section{Scopocoelidia gen. nov.}

Espécie-tipo: Scopocoelidia volsellata sp. nov.

Diagnose. Sutura coronal indistinta (Fig. 1); carena presente entre coroa e fronte; venação da asa anterior distinta, com quatro células apicais e três anteapicais (Fig. 4); asa posterior com veias $\mathrm{R}_{4+5}$ e $\mathrm{M}_{1+2}$ convergentes pré-apicalmente, fusionadas no ápice; genitália masculina: edeago com processo paralelo à haste na metade apical (Fig. 9); tubo anal com tufos de cerdas no ápice (Figs 5 e 10).

Descrição. Em vista dorsal, corpo estreitado, não achatado dorso-ventralmente.

Cabeça. Em vista dorsal, com coroa aproximadamente quadrangular, pouco projetada anteriormente, tão larga quanto longa (Fig. 1); margem anterior arqueada e fracamente angulada, quase arredondada, com carena na transição entre coroa e fronte; margens laterais, adjacentes aos olhos compostos, elevadas e levemente carenadas (Fig. 2); superfície plana, lisa, sem estrias, com máculas coronais fracamente visíveis; sutura coronal indistinta (Fig. 1); ocelos na margem anterior da cabeça, na transição entre coroa e fronte, acima dos lobos supra-antenais, mais próximos aos olhos compostos que da linha mediana, não visíveis em vista dorsal; lobos supra-antenais, em vista lateral, oblíquos e levemente carenados; flagelos antenais mais longos que a metade basal das asas anteriores; fronte com comprimento aproximadamente 1,5 vezes sua largura basal, perfil convexo, sem intumescimento central na base, não carenada; impressões musculares indistintas; suturas frontogenais atingindo os ocelos; margem apical da maxila ultrapas- sando o ápice do clípeo; loros aproximadamente semi-lunares, margens inferiores não atingindo o ápice do clípeo; genas não cobrindo completamente os proepisternos, estes visíveis em vista frontal apenas pelo ápice (Fig. 3); sutura epistomal distinta e completa, levemente arqueada; clípeo retangular, com margens laterais paralelas, sem intumescimento ou tubérculo apical e margem apical reta (Figs 2-3).

Tórax. Pronoto pouco mais largo que a cabeça, distância trans-humeral aproximadamente igual à distância transocular; comprimento mediano um terço da distância trans-humeral; margens laterais arredondadas, margem posterior emarginada (Fig. 1); superfície com estrias transversais; carena dorsopleural completa, curta e evidente (Fig. 2); mesotórax, em vista ventral, moderadamente intumescido; escutelo (sensu Young 1968) tão longo quanto sua largura máxima, com sulco distinto pré-apical. Asa anterior aproximadamente quatro vezes mais longa que sua largura máxima; com ápice arredondado; sem pontuações, hialina; venação distinta, com quatro células apicais, todas aproximadamente retangulares; segunda e quarta células apicais eqüidistantes da base, mais proximais que a terceira célula apical, esta última mais distal em relação à base; três células anteapicais, apenas a externa fechada; apêndice muito estreito, restrito à primeira célula apical (Fig. 4). Asa posterior com três células apicais, $\mathrm{R}_{4+5}$ e $\mathrm{M}_{1+2}$ convergentes pré-apicalmente, fusionando-se no ápice. Perna posterior: fórmula femoral $2+2+0$; tíbia: fileira PD densamente cerdosa, com cerdas longas e grossas, sem cerdas intercalares, uniformemente distribuídas por todo comprimento da tíbia; fileira $\mathrm{AD}$ com cerdas longas e grossas, espiniformes, com bases proeminentes e duas ou mais cerdas curtas intercalares; fileira AV com cerdas curtas e espiniformes, sem bases proeminentes, somente na metade apical da tíbia, cerdas intercalares ausentes; fileira PV densamente cerdosa, com cerdas curtas na base, alongando-se em direção ao ápice; tarsômero I tão longo quanto o comprimento da soma dos dois mais distais, com duas fileiras paralelas de microcerdas na superfície plantar.

Genitália masculina: pigóforo sem processos, com dente ventral no terço apical (Fig. 5); valva subgenital fusionada às placas subgenitais; placas subgenitais fusionadas nos terços basal e médio, separadas entre si somente no ápice (Fig. 6); estilos simples, não bifurcados, com ápice em forma de gancho pequeno, esclerosado, curvado ventralmente (Figs 7-8); conetivo em forma de "V" (Fig. 8); edeago com processo paralelo à haste na metade apical (Fig. 9); tubo anal com tufos de cerdas no ápice (Figs 5 e 10).

Comprimento total (corpo + asas anteriores): 5,0-6,0.

Distribuição geográfica. Brasil e Guiana Francesa.

Comentários. Scopocoelidia gen. nov. pode ser facilmente separado dos demais gêneros de Neocoelidiinae pela presença de tufos de cerdas no ápice do tubo anal (Figs 5 e 10). Dentre os gêneros de Neocoelidiinae, parece ser próximo a Coelidiana, ambos possuindo morfologia externa muito semelhante, sua separação sendo feita apenas com base no aspecto da genitália masculina.

Revista Brasileira de Zoologia 24 (1): 228-232, março 2007 

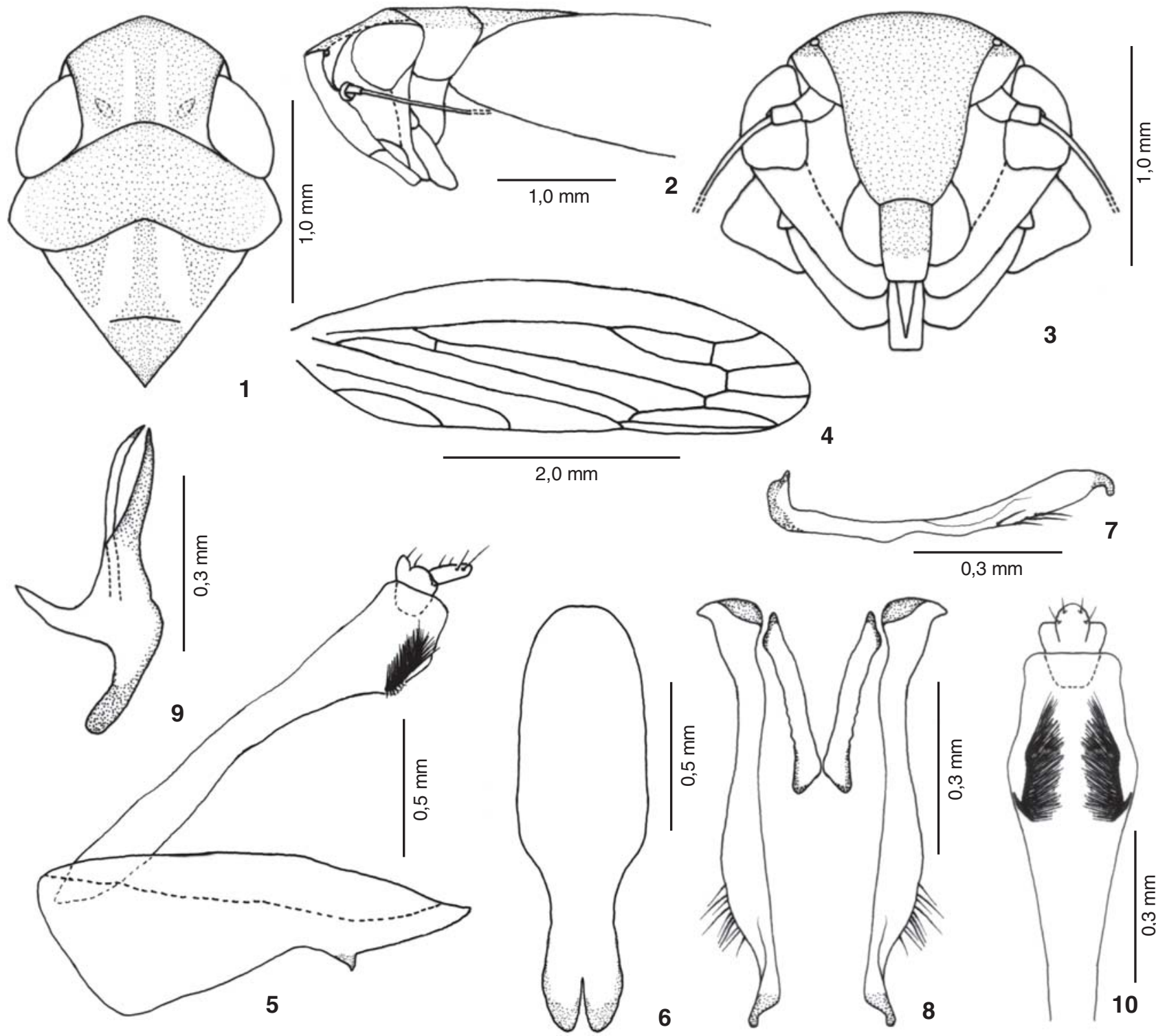

6
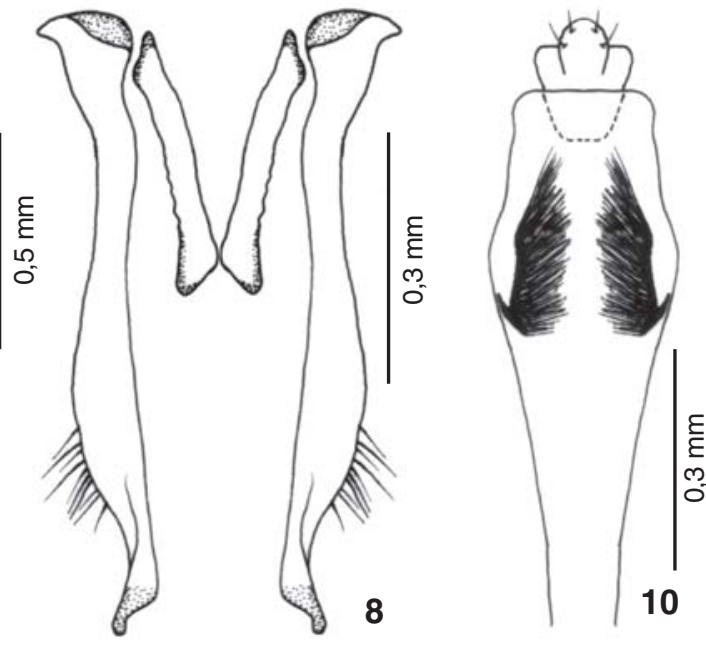

Figuras 1-10. Scopocoelidia volsellata sp. nov., holótipo macho: (1) cabeça, pronoto e escutelo, vista dorsal; (2) cabeça, pronoto e escutelo, vista lateral; (3) cabeça, vista frontal; (4) asa anterior; (5) pigóforo e tubo anal, vista lateral; (6) placas subgenitais, vista ventral; (7) estilo, vista lateral; (8) estilos e conetivo, vista dorsal; (9) edeago, vista lateral; (10) porção distal do tubo anal, vista ventral.

Etimologia. O nome do gênero é feminino e combina a palavra scopa, do latim = vassoura, com o sufixo -coelidia, comum a vários gêneros de Neocoelidiinae. Faz referência à presença de um tufo de cerdas no ápice do tubo anal, caráter exclusivo deste gênero.

\section{Scopocoelidia volsellata sp. nov.} Figs 1-11

Localidade-tipo: Manaus, Amazonas, Brasil.

Diagnose. Genitália masculina: pigóforo, em vista late- ral, aproximadamente triangular (Fig. 5); placas subgenitais fortemente estreitadas no terço apical (Fig. 6); ápice do estilo, em vista dorsal, com aspecto truncado (Fig. 8); edeago com haste muito estreita na metade apical, com processo mediano ventral lateral à haste, assemelhando-se ao formato de uma pinça (Fig. 9); tubo anal membranoso e longo (Figs 5 e 10).

Medidas. Holótipo macho: comprimento total 5,25; comprimento mediano da coroa 0,50 ; distância transocular 1,30 ; distância interocular 0,65; comprimento mediano do pronoto 0,45; distância trans-humeral 1,15; comprimento mediano do 


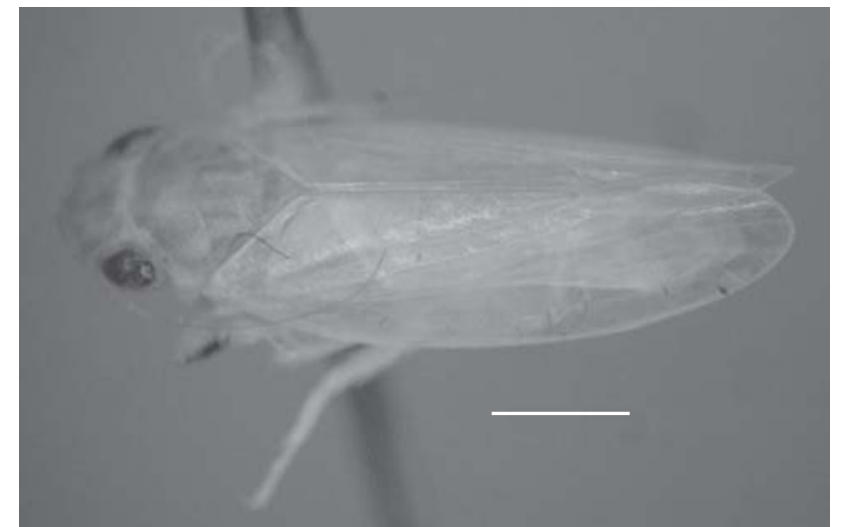

Figura 11. Scopocoelidia volsellata sp. nov., holótipo macho, vista láterodorsal. Escala $=1,0 \mathrm{~mm}$.

escutelo 0,85; largura máxima do escutelo 0,90; comprimento da asa anterior 4,37; largura máxima da asa anterior 1,15; largura basal da fronte 0,55; comprimento da fronte 0,70.

Descrição. Caracteres estruturais como na descrição genérica. Comprimento mediano da coroa aproximadamente igual à distância interocular e aproximadamente um terço da distância transocular; fronte com comprimento aproximadamente 1,5 vezes sua largura basal; distância trans-humeral aproximadamente igual à distância transocular; asa anterior com comprimento aproximadamente quatro vezes sua largura máxima. Genitália masculina: pigóforo, em vista lateral, aproximadamente triangular, com base alargada, estreitando-se gradativamente em direção ao ápice, e margem posterior angulada, sem cerdas (Fig. 5). Placas subgenitais aproximadamente triangulares, alargadas nos terços basal e médio e fortemente estreitadas no terço apical; ápices arredondados, com microcerdas; tão longas quanto o pigóforo; cada placa com comprimento aproximadamente seis vezes sua largura (Fig. 6); em vista lateral, sem dentes, com ápice não curvado para cima. Estilos longos e afilados, com fileira de cerdas na porção préapical da margem externa; margens sem ondulações; em vista dorsal, ápice com aspecto truncado (Figs 7-8). Conetivo cerca de metade do comprimento dos estilos, articulado à base do edeago (Fig. 8). Edeago, em vista lateral, com base alargada, com apódema dorsal afilado e pontudo; haste abruptamente muito estreitada na metade apical, levemente curvada ventralmente; processo mediano ventral pontiagudo e esclerosado, paralelo à haste e tão longo quanto esta; margem ventral do edeago lisa, sem dentes; gonóporo apical (Fig. 9). Tubo anal membranoso e longo, sem processos (Figs 5 e 10).

Fêmea. Desconhecida.

Coloração geral. Amarela; cabeça, em vista frontal, com fronte e clípeo amarelo-escuros a laranjas, o restante amarelo, sem manchas (Fig. 3). Coroa quase inteiramente laranja com duas manchas centrais amareladas; pronoto laranja, com ângulos laterais amarelados; escutelo amarelado, com manchas laranjas aproximadamente triangulares nos ângulos laterais e uma faixa longitudinal central da mesma cor, mais alargada no ápice (Fig. 1). Asa anterior amarela a esbranquiçada, com veias amareladas, margem anal e primeira célula apical amarelo-escuras a laranjas (Fig. 4). Asa posterior hialina, sem coloração distinta. Pernas amarelo-claras, sem manchas, com cerdas amarelas.

Distribuição geográfica. Brasil (Amazonas) e Guiana Francesa.

Material examinado. Holótipo macho (INPA): BrasiL, Amazonas: Manaus, ZF2, Km 14, Torre, 02³5'21"S, 6006'55”W, 16-19.VII.2004, lençol com luz mista, BL e BLB, 40 m de altura/ J.A. Rafael, C.S. Motta, F.F. Xavier Filho, A. Silva Filho e J.T. Câmara leg. Parátipos: idem, 1 macho (INPA); idem, 1821.II.2004, J.A. Rafael, C.S. Motta, F.F. Xavier Filho, A.F. Silva Filho e S. Trovisco leg., 1 macho (DZUP); Guiana Francesa: [Guyane], $33 \mathrm{~km}$ SE of Roura, on Kaw R[oa]d, 01.XII.2002, J.E. Eger leg./ $04^{\circ} 34.135^{\prime} \mathrm{N}, 52^{\circ} 11.150^{\prime} \mathrm{W}, 227 \mathrm{~m}, \mathrm{MV}$ light, 1 macho $(\mathrm{MNHN})$.

Condição do holótipo. Lateral direita do tórax colada diretamente em alfinete entomológico com cola branca comum; antenas com flagelos quebrados na metade apical; pernas e asas em perfeito estado de conservação; abdome dissecado.

Variações. Apenas na coloração externa: um parátipo, da localidade-tipo, apresentou coloração geral quase que inteiramente amarelo-escura a laranja; o outro parátipo, da mesma localidade, tem coloração semelhante à do holótipo, mas com pronoto amarelo-escuro. O parátipo da Guiana Francesa apresentou as manchas da coroa, pronoto e escutelo mais bem definidas, sendo amarelado, com três faixas longitudinais estendendo-se da coroa ao escutelo, a faixa central estreita, alargada somente no ápice do escutelo, duas faixas laterais mais largas e uma faixa laranja transversal na margem anterior da coroa, unida às demais faixas.

Comentários. Quanto à morfologia externa, assemelhase muito às espécies de Coelidiana. Entretanto, pode ser facilmente separada das demais espécies de Neocoelidiinae pela morfologia da genitália masculina, principalmente, pelo aspecto do edeago e do tubo anal (Figs 5, 9 e 10).

Etimologia. Do latim, volsella $=$ pinças, $-a t a=$ sufixo de posse, daí o nome volsellata, referindo-se ao formato do edeago, que por possuir um processo longo e pontiagudo paralelo à haste, assemelha-se ao formato de uma pinça.

\section{AGRADECIMENTOS}

A José A. Rafael e Augusto L. Henriques (INPA) e Paul H. Freytag (University of Kentucky, Estados Unidos) pelo empréstimo dos espécimes. À Lúcia M. de Almeida e Cibele S. Ribeiro-Costa por gentilmente permitirem o uso do equipamento fotográfico pertencente ao seu laboratório. Ao Conselho Nacional de Desenvolvimento Científico e Tecnológico pela bolsa de doutorado concedida à primeira autora e pela bolsa de produtividade concedida ao segundo autor.

Revista Brasileira de Zoologia 24 (1): 228-232, março 2007 


\section{REFERÊNCIAS BIBLIOGRÁFICAS}

Comstock, J.H. \& J.G. Needham. 1898. The wings of insects. American Naturalist 32: 43-48, 81-89, 231-257, 335-340, 413424, 561-565, 768-777, 903-911.

Comstock, J.H. \& J.G. NeEdHAm. 1899. The wings of insects. American Naturalist 33: 117-126, 573-582, 845-860.

Dietirch, C.H. 2003. Some unusual Neotropical Neocoelidiinae with a redefinition of the subfamily (Hemiptera: Membracoidea: Cicadellidae). Annals of the Entomological Society of America 96 (6): 700-715.

Dietirch, C.H. 2004. Phylogeny of the leafhopper subfamily Evacanthinae with a review of Neotropical species and notes on related groups (Hemiptera: Membracoidea: Cicadellidae). Systematic Entomology 29: 455-487.

Hamilton, K.G.A. 1981. Morphology and evolution of the rhynchotan head (Insecta: Hemiptera, Homoptera). Canadian Entomologist 113: 953-974.

KRAmer, J.P. 1964. A generic revision of the leafhopper subfamily Neocoelidiinae (Homoptera: Cicadellidae). Proceedings of the United States National Museum 115: 259-287.

Marques-Costa, A.P. \& R.R. CAVICHIOLI. 2006. Revisão taxonômica, análise cladística e descrição de espécies novas de Aglaenita Spinola (Hemiptera, Cicadellidae, Neocoelidiinae). Revista Brasileira de Entomologia 50: 355-378.

Mejdalani, G. 1998. Morfologia externa dos Cicadellinae
(Homoptera: Cicadellidae): comparação entre Versigonalia ruficauda (Walker) (Cicadellini) e Tretogonia cribrata (Melichar) (Proconiini), com notas sobre outras espécies e análise da terminologia. Revista Brasileira de Zoologia 15: 451-544.

Nielson, M.W. \& W.J. KNIGHT. 2000. Distributional patterns and possible origin of leafhoppers. (Homoptera, Cicadellidae). Revista Brasileira de Zoologia 17: 81-156.

Oman, P.W. 1949. The Nearctic leafhoppers (Homoptera: Cicadellidae). A generic classification and check list. Memoirs of the Entomological Society of Washington 3: 1-253.

RAKITOV, R.A. 1998. On differentiation of cicadellid leg chaetotaxy. Russian Entomological Journal 6: 7-27.

Triplehorn, C.A. \& N.F. Johnson. 2005. Borror and Delong's Introduction to the Study of Insects. Belmont, Thomson Brooks/Cole, $7^{\text {th }}$ ed., 864p.

Young, D.A. 1968. Taxonomic study of the Cicadellinae (Homoptera, Cicadellidae). Part 1. Proconiini. Bulletin of the United States National Museum 261: 1-287.

Young, D.A. 1977. Taxonomic study of the Cicadellinae (Homoptera: Cicadellidae). Part 2. New World Cicadellini and the genus Cicadella. Bulletin of the North Carolina Agricultural Experiment Station 239: VI+1135p.

Young, D.A. 1986. Taxonomic study of the Cicadellinae (Homoptera: Cicadellidae). Part 3. Old World Cicadellini. Bulletin of the North Carolina Agricultural Experiment Station 281: 1-639.

Recebido em 14.XI.2006; aceito em 08.III.2007. 